\title{
RECEPC̃̃O E LEITURA: BREVE RELATÓRIO SOBRE O ESTADO DE SAÚDE DA LITERATURA BRASILEIRA NA ITÁLIA DE HOJE
}

Elisa ALBERANI

\begin{abstract}
RESUMO
O objetivo deste artigo é proporcionar uma reflexão sobre os conceitos de recepção e leitura através de um breve histórico das principais abordagens, do passado e contemporâneas e aplicá-las a uma reflexão sobre a recepção da literatura brasileira na Itália de hoje. O texto apresenta algumas considerações sobre fatores que influenciam essa recepção, nomeadamente: determinantes sociais, cânone e tradução, para chegar a uma reflexão mais específica sobre a realidade da recepção da literatura brasileira contemporânea na Itália atual e o papel do leitor.
\end{abstract}

PALAVRAS-CHAVE: Recepção; Leitura; Literatura Brasileira; Itália; Século XXI.

\section{RECEPTION AND READING: BRIEF REPORT ON THE 'HEALTH'OF BRAZILIAN LITERATURE IN TODAY'S ITALY}

\begin{abstract}
The purpose of this paper is to provide a reflection on the concepts of reception and reading through a brief historical digression of the main past and contemporary considerations on these themes. The text presents some considerations about factors that influence the reception, namely, social determinants, canon and translation, to reach a more specific reflection on the reality of the reception of contemporary Brazilian literature in Italy and the role of the reader.
\end{abstract}

KEYWORDS: Reception; Reading; Brazilian literature; Italy; 21st century.

\section{RICEZIONE E LETTURA: BREVE RESOCONTO SULLO STATO DI SALUTE DELLA LETTERATURA BRASILIANA NELL'ITALIA DI OGGI}

\begin{abstract}
Lo scopo del presente articolo è quello di fornire una riflessione sui concetti di ricezione e lettura attraverso una breve digressione storica degli approcci teorici, passati e contemporanei, su questi temi. Il testo propone alcune considerazioni sui fattori principali che influenzano la ricezione, in particolare i determinanti sociali, il canone e la traduzione, per poi esemplificare quanto esposto in una realtà più specifica, ossia la ricezione della letteratura brasiliana contemporanea in Italia in questo nuovo secolo, e cercare di capire il ruolo del lettore italiano.
\end{abstract}

PAROLE CHIAVE: Ricezione; Lettura; Letteratura brasiliana; Italia; XXI ${ }^{\circ}$ secolo.

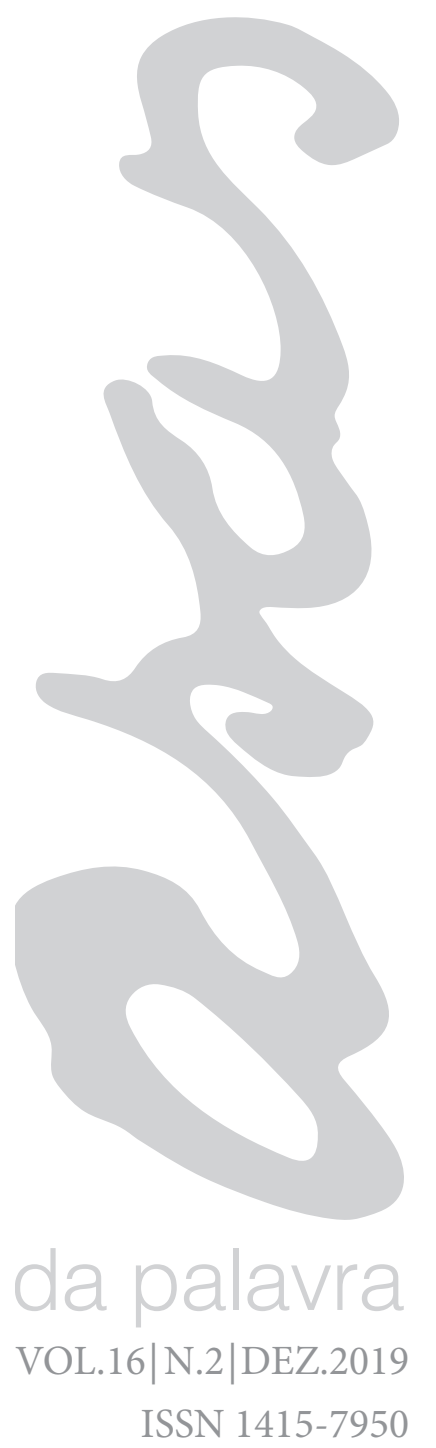


One writes only half the book; the other half is with the reader. (Joseph Conrad)

1 Tradução nossa em português. Segue o original: "si [..] designa il contributo semantico che il lettore, con le sue attese, le sue conoscenze e la sua interpretazione, dà alla vita di un testo".

2 Texto original: "cambiano di epoca in epoca a causa anche delle mode, della cultura dei lettori, delle tecnologie editoriali, luoghi e contesti politici”.

É sempre uma tarefa difícil analisar e compreender a recepção de uma literatura estrangeira na Itália de hoje e a análise receptiva da literatura brasileira não constitui exceção. Isto, principalmente, porque é preciso ter em conta muitos fatores diferentes, tais como determinantes sociais, cânone, tradução, além da qualidade da leitura e dos leitores, neste caso, italianos. O nosso ponto de partida é, portanto, uma reflexão sobre os conceitos de recepção e leitura em geral, para depois entrar mais especificamente nas questões relativas a políticas de tradução e editorias, para, finalmente, tentar aplicar as considerações surgidas a uma apreciação sobre a leitura 'real' de autores brasileiros em tradução italiana, do ponto de vista sociológico.

\section{A RECEPÇÃO LITERÁRIA ENTRE DETERMINANTES SOCIAIS, LEITOR E LEITURA}

Antigamente, costumava-se falar de fortuna de um texto literário, significando o que atualmente é chamado de recepção de uma obra. Se com fortuna se indica o percurso de uma obra ao longo do tempo, é com o termo recepção que se designa uma reconstrução e uma releitura de uma obra que vem do passado, e é com esse último conceito que "se [...] designa a contribuição semântica que o leitor com suas expectativas, seus conhecimentos e a sua interpretação, dá a vida de um texto"1 (GARDINI, 2002, p. 38). A partir dessa definição, fica claro quanto a literatura contém uma ideia sociológica, diretamente relacionada à função - definível como social - dos textos, na qual a fortuna de um autor está diretamente ligada à sua recepção e, em parte, à sua publicação. O que muda a recepção de um autor ou de uma obra, são alguns mecanismos muito complexos que "mudam em cada época também por causa das modas, da cultura dos leitores e das tecnologias editoriais, lugares e contextos políticos" (p. 39) ${ }^{2}$, afetando sua vida futura ou seu desaparecimento. Na contemporaneidade, desde que o autor se tornou um dos atores fundadores do processo literário, também a maneira como o texto é recebido mudou muito: é fundamental diferenciar a chamada recepção 'coletiva', que é o público, esse grupo indistinto de pessoas a quem uma obra é dirigida, da recepção 'individual', que 
indivíduo para indivíduo e que tornam os vários receptores peculiares e heterogêneos. É justamente por causa da heterogeneidade do público que a recepção também pode ser pensada como um "mal-entendido [que] depende do nível de conhecimento com o qual o leitor participa do 'projeto literário' do autor" (p. 40)³. Esta diferença de recepção, entre o público e o leitor, é fundamental para uma análise adequada: a recepção do público deve ser considerada um fenômeno social e requer uma atenção predominantemente histórica e sociológica, enquanto a recepção do leitor está relacionada à experiência do indivíduo que lê e prevê uma abordagem fenomenológica e hermenêutica (CADIOLI, 1998, p. 12).

A recepção é fortemente influenciada por inúmeros fatores sociais, chamados por Lowenthal de 'determinantes sociais': esses são elementos que medem os efeitos de um trabalho sobre o público (LOWENTHAL, 1977, p. 241), por exemplo, a influência da constelação social no leitor. Nesse caso, a análise se dá a partir de como os diferentes períodos históricos e as respectivas situações de estabilidade ou instabilidade política influenciam a recepção de um determinado texto, ou como as modalidades do sistema de distribuição levam ao sucesso de uma obra. Igualmente essencial é o estudo da relação entre a literatura distribuída e aquela efetivamente consumida. Uma distribuição que muitas vezes é influenciada pelo sucesso do autor (uma fama ligada à atribuição de prêmios literários, ou aparições na mídia). Não devemos esquecer como as formas oficiais de controle, a censura por exemplo, afetam a distribuição de uma obra, acompanhadas por formas não oficiais, como resenhas, comentários críticos ou simples fofocas.

O italiano Vittorio Spinazzola, partindo das perspectivas críticas de Lowenthal, enfoca uma sociologia real da recepção, entendida como o estudo "da fortuna ou infortúnio encontrado pelo projeto literário nos diversos níveis de competências na qual se manifesta o juízo crítico, das elites especializadas aos simples 'consumidores' de base" (CADIOLI, 1998, p. 20)4. Um texto encontra sua realização quando observa a função para a qual foi concebido e atinge seu público (não apenas confirmando seu gosto, mas também o derrubando). Um texto que, nesse caso, torna-se o ponto de encontro entre autor e leitor. Nos trabalhos dos estudiosos mencionados, os leitores e, portanto, o próprio ato de ler, são considerados parte integrante e essencial do
3 Texto original: "fraintendimento [che]. dipende dal livello di intelligenza con cui il lettore partecipa al 'progetto letterario' dell'autore".
4 Texto original: "della fortuna o sfortuna incontrata dal progetto letterario ai diversi livelli di competenza in cui si manifesta il giudizio critico, dalle élites specialistiche ai semplici 'consumatori' di base". 
processo artístico, através de uma mutação da concepção do texto entendida como um organismo ativo e instável. Assim, o leitor se torna uma personagem implícita da obra, mas sobre cuja identidade o texto geralmente fornece muitas pistas através de referências subjacentes: uma ideia que lembra o 'leitor modelo' de Umberto Eco (2002), que leva a abordar as diferenças entre os vários tipos de leitor.

É habitual atribuir a Hans Robert Jauss (1988) a elaboração de uma nova teoria histórico-literária. Segundo esta, o problema da recepção através da criação de uma estética que analise a fruição literária, vista como prazer, atribui à literatura uma função purificadora e aos leitores um papel fundamental no mecanismo de recepção da obra literária. Uma avaliação, portanto, não apenas do texto, mas também e sobretudo de sua recepção pelo público, com especial atenção na identificação e análise da efetividade do trabalho através do conceito de horizonte de espera - recuperação, mesmo que com algumas diferenças, do conceito Gadameriano de horizonte (CASADEI, 2001, p. 133-134).

A abordagem desenvolvida por Jauss, se concentra em vários temas interconectados, que levam ao surgimento de uma estética da recepção. Antes de tudo, ele afirma que a qualidade de uma obra literária resulta dos critérios de recepção, do efeito produzido e de sua reputação - incluindo a póstuma (JAUSS, 1988, p. 7). Os mecanismos de recepção envolvem dois momentos essenciais na realização de uma obra literária: a de sua elaboração e a de sua atualização. A análise do processo de recepção levará em conta tanto o nível sincrônico quanto o diacrônico, estudo que destaca a importância das funções históricas e sociais de uma obra. Para Jauss, são elementos de análise o objeto textual, o sujeito que esse texto produz e o sujeito que o recebe. Há então implicações históricas e estéticas na relação entre literatura e leitor. A obra literária é criada pela leitura, não é um objeto que existe como tal e, portanto, faz parte de um processo dinâmico no qual até as reações dos leitores provocadas pelo texto e os consequentes julgamentos se tornam fundamentais.

Uma abordagem parcialmente diferente é proposta por Wolfgang Iser (1989). Para ele, o leitor tem um papel ainda mais central em relação às teorias jaussianas, porque seu foco principal é o próprio ato da leitura. $\mathrm{O}$ aspecto interessante, e ao mesmo tempo inovador, diz respeito à ideia do leitor como participante ativo da criação de um objeto estético durante a leitura. $\mathrm{O}$ verdadeiro protagonista do processo de leitura e, 
portanto, interpretativo, é o leitor, um leitor implícito, não real, um destinatário ideal do texto. Segundo Iser (1989), a tarefa da crítica não é explicar o texto como um objeto, mas os efeitos que o texto causa no leitor: a relação leitor-texto se torna assim fundamental, enfatizando a função comunicativa de um obra literária e sua relação com o contexto histórico-cultural. Assim como para Jauss, também Iser defende que as expectativas têm um papel fundamental no processo de leitura e são precisamente elas que mudam o horizonte de espera. Assim, o texto é concluído apenas quando o leitor lê e toma consciência do que ele possui, dando-o um sentido. Toda leitura é, portanto, provisória, uma vez que não se esgotam completamente as compreensões de estruturas e significados contidos no texto. O leitor, lendo, cria significados que de outra forma não seriam produzidos. O significado é dado apenas pelo sujeito que lê e não existe independentemente dele. Isso também leva ao pressuposto da existência de infinitas leituras possíveis, uma vez que os significados são criados pelo leitor a cada nova leitura e, assim, as potencialidades da interpretação são infinitas. Privilegiando a relação autor-obra-público, os teóricos da Escola de Constança ${ }^{5}$ similarmente enfatizam a relação sociedade-leitor: a valorização do leitor o coloca plenamente no processo interpretativo da obra literária, se tornando parte ativa dele.

O surgimento de interesses hermenêutico-interpretativos, sociais e econômicos, são elementos analisados com particular interesse pelo sociólogo francês Robert Escarpit que, no final da década de 1950, aproxima a ideia de literatura à questão mais material de mercado do livro, combinando a economia com o texto literário tradicional. O pai da sociologia da literatura lidou com as diferentes maneiras pelas quais uma obra literária pode ser usufruída, levando a um interesse cada vez mais atento por esse assunto que condicionará muitas das orientações subsequentes. O estudioso insere o problema da recepção em um contexto sociológico e combina a ideia da leitura com a do consumo, analisando as obras literárias sob uma perspectiva socioeconômica. A atenção se focaliza na materialidade da literatura, que inclui tanto a análise das características culturais de um determinado período histórico, quanto o estudo de dados de vendas e circulação, para entender os gostos e tendências do público. Se os estudos de Escarpit podem ser considerados uma primeira abordagem para os problemas de recepção, uma vez que levam em consideração a fruição da obra
5 A Escola de Constança é uma escola de diálogo interdisciplinar fundada no final dos anos sessenta, principalmente por Hans Robert Jauss e Wolfgang Iser e que reúne em torno da revista Poetik und Hermeneutik um grupo de estudiosos de diferentes disciplinas. 
6 Original: "Considerare l'oggetto libro e il testo la stessa cosa".
7 Original: "complementari: come certe collettività leggano un testo particolare e quali scale di valori (quali ideologie) influenzino le loro letture".

8 Original: "una catena di artifici espressivi che debbono essere attualizzati dal destinatario".

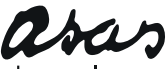

VOL. 16 | N.2 | DEZ. 201 da palavra ISSN 1415-7950

literária, é necessário destacar o perigo que esse tipo de abordagem pode trazer, a saber, a ideia errônea de que haja correspondência direta entre consumo e recepção, isto é, "considerar o objeto livro e o texto a mesma coisa" (GARDINI, 2002, p. 41)6. A ideia subjacente às teorias de Escarpit é de origem sartriana, tendo condição necessária e suficiente para a existência de um livro, a sua leitura. Mesmo assim, segundo o estudioso, para estudar adequadamente a literatura, devemos levar em consideração toda a dinâmica mais material do mundo editorial, como produção, distribuição e consumo. Deste modo, entendendo o texto como um fato social, o estudo da fruição e recepção de uma obra se torna fundamental para a compreensão mais profunda dos mecanismos do nexo literatura-sociedade. Um livro não satisfaz uma necessidade coletiva identificável, como qualquer outro tipo de produto, e aqui está a motivação pela qual o mercado literário é particularmente complicado. Uma crítica que pode ser avançada à abordagem de Escarpit é a de negligenciar dois elementos definíveis como "complementares: como certas coletividades leem um determinado texto e quais escalas de valores (quais ideologias) influenciam essas leituras" (ZIMA, 1986, p. $167)^{7}$.

Roland Barthes (1988) ao declarar 'a morte do autor', sublinha o papel do leitor como o único criador possível de significado de uma obra: um leitor livre, com extrema liberdade diante de um texto, mas nunca inocente. $\mathrm{O}$ autor e o texto se afastam e o texto é concebido como um espaço com inúmeras dimensões, o que pode levar a múltiplas interpretações diferentes, pois o leitor sempre produz novas leituras.

Encontramos um desenvolvimento adicional das teorias sobre o papel do leitor e sobre a leitura, no pensamento de Umberto Eco (2002), que partindo das reflexões dos teóricos da Escola de Constança e condenando em parte as teorias mais radicais sobre a resposta do leitor, sustenta que o texto não pode ser lido de uma maneira completamente arbitrária porque oferece pontos de referência. Eco teorizou - em particular no trabalho Lector in fabula - um leitor modelo, contemplando o texto como "uma cadeia de artifícios expressivos que devem ser atualizados pelo destinatário" (p. 50) ${ }^{8}$. Uma definição que enfatiza o papel do leitor, que é questionado na realização do texto, por meio de competências gramaticais. Paralelamente à ideia de um leitor modelo, há também a de um autor modelo, formulado pelo leitor empírico: entre esses dois atores, ou melhor, entre essas estratégias discursivas, 
REVISTA DO PROGRAMA DE PÓS-GRADUAÇÃO EM COMUNICAÇÃO, LINGUAGENS E CULTURA DA UNIVERSIDADE DA AMAZÔNIA

deve haver uma cooperação interpretativa - cujos processos já estão configurados nos traços do texto -, o que sublinha a importância da intervenção do leitor para construir o significado de um texto, levando a uma transformação do próprio ato de ler que "não estaria mais em descobrir quais são as intenções do enunciador manifestadas no texto, mas na atualização das possibilidades virtuais de sentido que estão presentes no texto" (p. 50) ${ }^{9}$. Na teoria de Eco,o texto "não admite ser interpretado em infinitos modos concebíveis, mas se coloca sempre como o parâmetro das interpretações possíveis" (PISANTYPELLEREY, 2004, p. 359). ${ }^{10}$

É nas últimas décadas então, que o leitor assumiu um papel central na reflexão crítica. A mudança de perspectiva viu a alteração de um foco no par autor-texto para a dupla leitor-texto. São válidas as bases metodológicas pelas quais Jauss pretendia chegar a uma avaliação completa do papel do receptor e das modalidades de posse de textos literários, mas é possível fazer algumas críticas às teorias da Escola de Constança, sobretudo pelo fato desta ignorar o processo de produção intertextual do qual resultou o texto. Será fundamental destacar a estreita relação que existe entre produção e recepção e a necessidade de levar em conta estruturas textuais (semânticas e sintáticas), se pretendermos explicar uma recepção específica. Através das respostas dos leitores às perguntas feitas pelo autor, se estabelece o caráter dialógico, isto é, a característica fundadora de todo ato de comunicação literária: "Uma comunicação que, se entendida entre o presente e o passado, permanece sempre condicionada ao horizonte histórico do intérprete" (JAUSS, 1988, p. 145).

\section{O PAPEL DO CÂNONE E DA TRADUÇÃO NA RECEPÇÃO}

Um elemento inevitável, do qual Harold Bloom parece ter esquecido ao compilar seu Cânone Ocidental (1995), é o fato de que muitas das obras incluídas em seu cânone terem sido lidas em tradução, excluindo assim, toda uma série de obras escritas em idiomas sem uma tradução acessível. Tal exemplo mostra que a tradução é um meio essencial para inclusão ou exclusão no cânone. A ligação entre cânone e a recepção está, também, inextricavelmente ligada ao conceito de tradução. As traduções participam ativamente na construção do cânone e na sua transformação, pois representam um meio fundamental "para introduzir em uma cultura, formas narrativas
9 Original: "non consiste più nello scoprire quali siano le intenzioni dell'enunciatore manifestate nel testo, ma nell'attualizzare le possibilità virtuali di senso che nel testo sono presenti".

10 Original: "non ammette di essere interpretato in qualunque modo concepibile, ma si pone sempre come il parametro delle sue interpretazioni possibili”. 
11 Original: "per introdurre in una cultura forme narrative e paradigmi estetici stranieri, e possono anche avere un ruolo significativo nell'importazione di concetti e teorie letterarie, che a loro volta possono stimolare il bisogno di rivedere e riformare i canoni tradizionali".

12 Original: "conformandosi o opponendosi a essi, partecipando al loro continuo processo di trasformazione e rinnovamento".

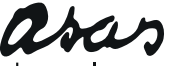

VOL. $16 \mid$ N.2 | DEZ.201 ISSN 1415-7950 e paradigmas estéticos estrangeiros, e podem também ter um papel significativo na importação de conceitos e teorias literárias, que por sua vez podem estimular a necessidade de rever e reformar os cânones tradicionais" (NERGAARD, 2011, p. 108) ${ }^{11}$.

O teórico da tradução André Lefevere (1992) tratou da relação entre tradução e cânone, em particular em relação às reescritas, incluindo a tradução nesta categorização. Essas reescritas são consideradas formas fundamentais de mediação para que um trabalho seja aceito e inserido no cânone e, dentre elas, certamente a tradução tem um papel substancial, pois são os tradutores que trabalham com base em avaliações pessoais e levam à canonização de certas obras literárias. Remo Ceserani (1995) também compartilha esse ponto de vista, atribuindo uma forte responsabilidade às instituições na formação dos cânones. Para Ceserani, as instituições sociais encarregadas de transmitir cultura, em particular a escola e a universidade, são as que mais influenciam e determinam a canonização de certas obras (1995, p. 71).

Os trabalhos são traduzidos de acordo com estratégias precisas, às vezes justamente em função de sua inclusão no cânone, que também depende decisivamente do momento histórico em que uma obra é produzida e recebida. As ideologias condicionam e modificam os parâmetros que as obras devem possuir para a canonização, e essa afeta consequentemente também a seleção de obras a serem traduzidas. Como um círculo vicioso, se não traduzidas para idiomas veiculares como o inglês, dificilmente podem fazer parte do cânone. As escolhas feitas pelo tradutor, mas também as feitas pelo editor ou pelo crítico, se relacionam diretamente com os cânones "conformando-se ou se opondo a eles, participando de seu contínuo processo de transformação e renovação" (NERGAARD, 2011, p. 112). ${ }^{12}$

Através da tradução, o cânone não pode permanecer inalterado, uma mudança que também afeta a influência da cultura da chegada e a visão que essa cultura tem sobre a cultura de partida; um processo complexo que envolve o encontro de muitos fatores diferentes e no qual, o papel da tradução é fundamental, cheio de potencialidades, exatamente porque pode desempenhar a função de formar identidades culturais e construir certas representações de outras culturas.

Este último aspecto foi tratado por Lawrence Venuti (2002), enfatizando como a escolha de alguns textos - e a consequente exclusão de outros -, bem como o uso de certas estratégias de tradução, podem 
criar um cânone que frequentemente reflete os valores estéticos da cultura de chegada. Para Venuti, a tradução é uma espécie de filtro, pois leva à construção de figurações peculiares das literaturas estrangeiras.

Então, como transformar o cânone hegemônico? Talvez traduzindo aquelas obras que representam uma alternativa ao cânone dominante. A escolha ou exclusão do cânone, ou seja, os trabalhos a serem traduzidos, também dependem muito das escolhas feitas pela indústria editorial: o mercado e os consequentes aspectos, também econômicos, são elementos essenciais na formação do cânone. O elemento econômico influencia fortemente a fixação de certos cânones, mas o caminho seguido nos últimos sessenta anos pela indústria editorial não foi de todo homogêneo, pelo contrário, sofreu mudanças drásticas que modificaram o conceito de atividade editorial e crítica, embora ainda sejam dois elementos que contribuem fortemente para a canonização dos textos.

No período que vai desde os anos 1970 até hoje, todavia, estas duas formas de mediação cultural são quase incomparáveis: a crítica foi progressivamente contraindo a sua margem de ação social, ao contrário, a editoria se expandiu ao ponto de englobar os setores televisivo e digital, constituindo um universo comunicativo e mercadológico integrado que influencia a inteira vida cultural, social e econômica. (ZINATO, 2011, p. 75) $)^{13}$

Identidade cultural e tradução são elementos fortemente conectados que, por sua vez, estão intrinsecamente ligados ao conceito de cânone, ou melhor, à ideia da existência de uma multiplicidade de cânones e dos consequentes anticânones. Como reivindicado por Frye (1969), os cânones são, portanto, produtos constantemente provisórios e sujeitos a modificações contínuas para se adaptar a novas necessidades. Deve-se prestar atenção, no entanto, ao fato de que, embora o cânone não seja imutável e seja o resultado de um "determinado ideal educativo, [...] não tem como lógica consequência a precarização relativística" (MOTTA, 2009, p. 3). ${ }^{14}$

\section{A ATIVIDADE EDITORIAL ITALIANA: PROBLEMAS E TENDÊNCIAS}

A atividade editorial italiana segue um caminho bastante estruturado, marcado por eventos históricos e culturais de certa
13 Original: "Nel periodo che va dagli anni settanta a oggi, tuttavia, queste due forme di mediazione culturale sono pressoché inconfrontabili: la critica ha progressivamente contratto il suo margine di azione sociale, l'editoria al contrario si è espansa al punto da comprendere il settore televisivo e digitale, costituendo un universo comunicativo e merceologico integrato che influenza l'intera vita culturale, sociale, economica".

14 Original: "preciso ideale educativo, [...] non ha come logica conseguenza la precarizzazione relativistica". 
relevância. Reconstruindo, embora muito superficialmente, a história da atividade editorial italiana, é possível distinguir cinco períodos principais:

15 Original: “i) l'epoca pionieristica durata fino alla fine della seconda guerra mondiale, ii) un periodo di transizione fra il 1945 ed il 1958 , iii) la crescita della produzione durata fino al 1971 , iv) la fine dell'epoca degli editori pionieri e la normalizzazione del settore fra il 1971 ed il 1983 e, infine, v) il periodo contemporaneo".

16. Original: "Contribuiscono insieme a creare la figura dell'editore protagonista. Le figure di Arnoldo Mondadori, Angelo Rizzoli, Valentino Bompiani e Luigi Einaudi esprimono diverse combinazioni di mecenatismo e paternalismo con aziendalismo ed autoritarismo, con Mondadori ed Einaudi agli estremi opposti. Tutti però sono editori protagonisti, che personalizzano progetto e strategia della propria casa editrice, hanno amore per il buon libro e per il libro ben fatto e portano avanti una forte politica d'autore, stringendo legami personali con scrittori che, per lungo tempo, non avrebbero cambiato casa editrice".

17 Original: "Quando inizia un periodo di normalizzazione postbellica e di concentrazione delle piccole case editrici".

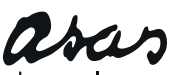

\begin{tabular}{l|l|l} 
VOL. $16 \mid$ N.2 | DEZ. 2019 & -19
\end{tabular}

da palavra ISSN 1415-7950 i) a época pioneira que durou até a Segunda Guerra Mundial; ii) um período de transição entre 1945 e 1958; iii) o crescimento da produção que durou até 1971; iv) o final da época dos editores pioneiros e a normalização do setor que se deu entre 1971 e 1983 e, enfim, v) o período contemporâneo. (PARESCHI, 2011, p. 30)15

No primeiro período relatado, particularmente nas primeiras décadas do século passado, há quatro homens que

\begin{abstract}
contribuíram para a criação da figura do editor protagonista. As figuras de Arnoldo Mondadori, Angelo Rizzoli, Valentino Bompiani e Luigi Einaudi expressam diversas combinações de mecenato e paternalismo com empreendedorismo e autoritarismo, com Mondadori e Einaudi nos extremos opostos. Todos, porém, editores protagonistas, que personalizaram o projeto e a estratégia da própria editora, com amor pelo bom livro e por um livro bem feito e levaram adiante uma forte política de autor, estreitando laços pessoais com escritores que, por longo tempo, não publicarão por outras editoras. (PARESCHI, 2011, p. 31) 16
\end{abstract}

Uma atividade editorial caracterizada por 'editores protagonistas' e o leitor não é o que estamos acostumados hoje, mas geralmente era um intelectual. Um setor fechado e de elite que passará por uma forte mudança já a partir de meados do século passado, em particular com o final da segunda guerra mundial. Uma mudança que tenta superar a dicotomia, ainda muito forte, entre 'alta' e 'baixa' cultura, sobretudo graças ao nascimento de novas editoras. Mas uma mudança que termina após um período muito curto "quando começa um período de normalização pós-guerra e de concentração das pequenas editoras" ( $p$. 31) ${ }^{1}$ \%. Se o período entre o final da década de 1950 e o início da década de 1970 pode ser lembrado como o período do boom editorial, nos anos seguintes, se abre um período de crise, que decretará o início de um tipo de edição mais 'industrial':

O processo implica gradualmente até os anos 1980 profundas transformações, no quadro de mudanças objetivas da sociedade e do mercado, e vem substituindo a forte personalização do projeto e do catálogo a uma espécie de dio ascoso, no qual decisões estratégicas são tomadas por forças políticas e econômicas, muitas vezes não rastreáveis nos organogramas e de acordo com planos que com frequência transcendem o destino do livro. 
Daqui um achatamento tendencial das diferenças. (FERRETTI, 2004, p. 226) ${ }^{18}$

Até esse momento, a figura do intermediário tinha uma importância especial, mas a partir da década de 1980, com uma profunda reorganização, que muitas vezes levou a inovações, mesmo nas escolhas editoriais, esse ator perdeu sua função e os intelectuais que até naquela época haviam desempenhado esse papel, vão sendo substituídos por gerentes que fazem do marketing o principal motivo da indústria editorial. No entanto, isso também levou à escolha de publicar novas obras em detrimento daquelas que já faziam parte do catálogo. Basta pensar que no ano de

1981, 75\% das vendas da Rizzoli foram constituídas por novidades, enquanto se reduz a vida dos livros nas livrarias. Diminui a atenção para a política autoral: são sempre mais numerosos os casos de migração de escritores entre as diversas editoras, enquanto é fraco o interesse pela formação do escritor através de seu crescimento dentro de uma editora. (PARESCHI, 2011, p.33) $)^{19}$

Outro aspecto interessante diz respeito ao nascimento de novas editoras na década de 1970: "entre 1970 e 1979, nascem 538 novas editoras, contra as $211 \mathrm{dos}$ dez anos anteriores. Crescem as massas aculturadas e, com elas, uma demanda variada [...]" (p. 34)20. Tal crescimento exponencial nos títulos publicados neste período leva a um aumento na importância da figura de mediadores no campo literário, que não são mais só intelectuais e estudiosos, mas são capazes de promover as obras através dos mais variados canais. Apesar do número muito alto de editoras na Itália, no final dos anos 1980, grande parte do mercado ficou concentrado nas mãos de poucos "ao ponto que em 1989, sete editores detinham 50\% do mercado" (p. 34) ${ }^{21}$. Uma espécie de renascimento das pequenas editoras ocorrerá apenas a partir de meados da década de 1990, e isso também levará ao retorno daquelas figuras, até agora quase desaparecidas, de curadores de coleções que tentam dar à editora um estilo peculiar e reconhecível, mesmo que a crescente mobilidade dos autores e a grande heterogeneidade dos livros produzam uma perda de identidade e de características próprias que determinam a especificidade de cada editora e que podem orientar o processo de seleção de livros a serem publicados.
18 Original: "Il processo comporta via via fino agli anni ottanta graduali ma profonde trasformazioni, nel quadro di cambiamenti oggettivi della società e del mercato, e viene sostituendo alla forte personalizzazione del progetto e del catalogo una sorta di dio ascoso, le cui decisioni strategiche vengono da forze politiche ed economiche, spesso non rintracciabili negli organigrammi e secondo disegni che spesso trascendono il destino del libro. Di qui un tendenziale appiattimento delle differenze".

19 Original: " 1981 , il 75\% delle vendite di Rizzoli è costituito da novità, mentre si riduce la vita a scaffale dei libri in libreria. Scema l'attenzione per la politica d'autore: sempre più numerosi sono $\mathrm{i}$ casi di migrazioni di scrittori fra diverse case editrici, mentre c'è scarso interesse per la formazione dello scrittore attraverso la crescita entro una casa editrice".

20 Original: "Fra il 1970 ed il 1979 nascono 538 nuove case editrici, contro le 211 dei dieci anni precedenti. Crescono infatti le masse acculturate e, con loro, una domanda variegata [...]".

21 Original: "al punto che nel 1989 bastano 7 editori per fare il $50 \%$ del mercato". 
22 Original: "- i lettori sono per lo più concentrati nelle regioni settentrionali e centrali e nelle fasce più giovani, sotto i 34 anni; - si tratta di persone con una disponibilità di risorse economiche e culturali piuttosto ampia, sia a livello di istruzione, sia di reddito e status; - essi sono attratti piuttosto fortemente dall'innovazione e presentano una buona propensione alla leadership, al successo, al miglioramento culturale e professionale; - chi legge, guarda la televisione meno della media, se è giovane; è nella media, nel caso degli adulti; l'abitudine ad assistere a spettacoli cinematografici presenta valori ben al di sopra della media, soprattutto tra i giovani; - il possesso e l'uso di apparati tecnologici è superiore alla media".

23 Original: "i nostri tassi di lettura sono di gran lunga inferiori a quelli di nazioni, come Estonia e Polonia, con un PIL pro capite assai più basso del nostro".

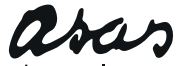

VOL. $16 \mid$ N.2|DEZ.2019 sobre o conceito de leitura de uma maneira bastante ampla e geral,

\footnotetext{
- os leitores estão concentrados nas regiões norte e central do país e nas faixas mais jovens, abaixo dos 34 anos; - trata-se de pessoas com disponibilidade econômica e cultural, relativamente ampla, tanto a nível de instrução, como de renda e status;

- são muito atraídos pela inovação e apresentam uma boa propensão à liderança, ao sucesso, ao melhoramento cultural e profissional;

- quem lê, assiste menos televisão do que a média da população, se é jovem; está na média, no caso dos adultos; com relação ao hábito de assistir espetáculos cinematográficos apresenta valores bem acima da média, sobretudo entre os jovens;

- a posse e uso de aparelhos tecnológicos é superior à média. (SOLIMINE, 2008, p. 236) ${ }^{22}$
}

Essa panorâmica confirma muitas das opiniões mais difundidas, embora não apoie a crença, errônea mas compartilhada, de que o uso da tecnologia substitui a leitura de um livro. Também é confirmado, considerando os fatores sociológicos expostos anteriormente, que o leitor italiano médio-forte tem um bom status socioeconômico, com níveis de renda médio-altos. Um dado, no entanto, todo italiano porque "os nossos índices de leitura são muito inferiores aqueles de nações como Estônia e Polônia, que possuem um PIB per capita muito menor que o nosso" (p. 236) ${ }^{23}$. Devemos ter presente que estamos falando

\section{O LEITOR ITALIANO: UM PERFIL NÃO MUITO CONFORTÁVEL}

Abordaremos agora, ainda que brevemente, a situação da leitura na Itália neste novo século, para entender a condição, certamente não entre as mais felizes, da recepção de autores brasileiros no território italiano. A qualidade da leitura, a partir do ano 2000, registrou uma tendência instável entre anos de crescimento no número de leitores e anos de declínio, mas, em geral, a situação, comparada à maioria dos países europeus, não é positiva. A leitura com a qual estamos lidando é a do tempo livre, portanto, não é uma leitura ligada a motivações profissionais ou escolásticas - se levássemos em consideração essa última em particular e, portanto, leituras relacionadas a estudos acadêmicos, a situação seria muito diferente porque as instituições acadêmicas italianas, mesmo se em número limitado, continuam a formar leitores de qualidade das 'coisas' brasileiras.

Quem são os leitores 'médio-fortes’ na Itália de hoje? Propomos a seguir uma imagem que resume as principais caraterísticas: da palavra ISSN 1415-7950 
referindo-se às teorias expressas em particular por Escarpit e Eco sobre o papel da leitura e do leitor e, portanto, não entraremos na questão, embora de interesse primário, do papel das bibliotecas na difusão da prática da leitura, pois exigiria ferramentas de investigação que são em parte diferentes daquelas relacionadas a um discurso mais global. Vamos apenas lembrar que "o desenvolvimento de um sistema moderno de bibliotecas de leitura pública, escolares e universitárias sejam condição imprescindível para o alargamento do perímetro do mercado da leitura, para o fortalecimento deste hábito, e em última instância ao desenvolvimento cultural e também econômico do país" (MOTTA, 2008, p. 64) ${ }^{24}$ e que, portanto, ainda há um longo caminho a ser percorrido em grande parte do território italiano, mas não faltam projetos importantes de certa escala e que são cada vez mais ativos e difundidos.

O aspeto no qual a Itália está na vanguarda, se refere à coleta de informações sobre a qualidade da leitura que o Istat (Istituto Nazionale di Statistica) ${ }^{25}$ fornece desde 1957. Decidimos examinar aqueles relacionados ao ano de 2017, publicados em dezembro de 2018 e que refletem as tendências observadas nos anos anteriores, com algumas flexões. Um fato interessante, que também influencia a chegada de obras de autores brasileiros à Itália, diz respeito ao fato de que "dos 1.459 editores ativos em 2017, quase $85 \%$ publica não mais de 50 títulos por ano. Mais da metade (54\%) são 'pequenos' editores, com um máximo de 10 obras em um ano, e 31\% são editores de médio-porte, [mas], os 'grandes' editores, com mais de 50 obras ao ano, [...] publicam mais de $80 \%$ dos títulos que estão no mercado e cerca de $90 \%$ das cópias impressas" (REPORT ISTAT, 2018, p. $1)^{26}$. Esses são dados que também afetam a distribuição e, em certa medida, o consumo 'real'. Os grandes editores geralmente mostram alguma resistência em aceitar e oferecer produtos de jovens autores, especialmente se eles vêm do outro lado do oceano. Por outro lado, muitos pequenos editores têm esse desejo de desafio e novidade em seu DNA, mas precisam lidar com custos nem sempre acessíveis e uma distribuição bastante limitada.

Outro elemento interessante é que há um sinal de relançamento na produção editorial, mesmo que isso afete apenas os grandes editores. Dados que, de qualquer forma, confirmam o crescimento do mercado de livros em geral a partir de 2015, após um longo período
24 Original: "lo sviluppo di un moderno sistema di biblioteche di pubblica lettura, scolastiche e universitarie sia condizione imprescindibile all'allargamento del perimetro del mercato della lettura, al rafforzamento della sua abitudine, e in ultima istanza allo sviluppo culturale ed anche economico del paese".

25 Todos os dados estatísticos relatados neste artigo estão presentes no relatório Istat: Produzione e Lettura di Libri in Italia (2018).

26 Original: “dei 1.459 editori attivi nel 2017, quasi 1'85\% pubblica non più di 50 titoli all'anno. Oltre la metà (54\%) sono 'piccoli' editori, con un massimo di 10 opere in un anno, e il 31\% sono 'medi' editori, [ma] i "grandi" editori, con oltre 50 opere all'anno, $[\ldots]$ pubblicano più dell' $80 \%$ dei titoli sul mercato e circa il $90 \%$ delle copie stampate". 
de recessão, mas que mostra claramente a dificuldade das pequenas editoras. A leitura diminuiu ligeiramente em comparação com o período bienal 2010-2012, que teve um crescimento bastante significativo e, de qualquer forma, falamos de percentuais que nunca atingem $50 \%$. Em 2017, apenas $41 \%$ das pessoas (com mais de 6 anos), leram pelo menos um livro por razões não profissionais. Há muitos anos, a população feminina tem demonstrado maior inclinação para ler $(47,1 \%$ das mulheres, contra $34,5 \%$ dos homens, leem pelo menos um livro durante o ano). Fica claro que a leitura continua sendo o problema central, uma vez que os leitores 'fortes' permanecem estáveis e apenas os leitores 'fracos' aumentam, os quais, obviamente, também são compradores fracos. Todos os dados amplamente demonstrados pelos estudos da OCDE-PISA (Programme for International Student Assessment), aliás, fornecem uma visão geral das habilidades de compreensão de textos e leitura de italianos, que são as mais baixas entre os países 'avançados'. É interessante notar também que os entrevistados dizem que não leem por causa de tédio, falta de tempo, preferência por outros entretenimentos e apenas um percentual bastante pequeno $(8,5 \%)$ por causa dos custos dos livros. Confirmando que os recursos econômicos não são a causa direta da falta de hábitos de leitura, mas o são principalmente fatores culturais.

O que fazer então? As soluções certamente não são fáceis, mas, com o passar dos anos, crescem cada vez mais a oferta de projetos de leitura, festivais para crianças e adultos de ótima qualidade. A percepção, no entanto, é que estes visam os leitores já 'fortes' e não lutam para atrair leitores 'fracos' ou não leitores. Certamente, estratégias devem ser implementadas para educar pais e professores dos futuros leitores, para que eles se tornem leitores efetivos quando adultos.

\section{LER AUTORES BRASILEIROS NA ITÁLIA DE HOJE: QUAIS PERSPECTIVAS?}

Para entender a situação da publicação e da leitura em referência a livros de autores brasileiros, é importante fornecer algumas premissas. Em primeiro lugar, uma situação não positiva de leitura por parte dos italianos, não pode certamente corresponder uma situação rósea de autores brasileiros traduzidos, exceto por alguns nomes bem conhecidos. Em segundo lugar, é importante sublinhar que não é fácil encontrar todos os títulos traduzidos, porque não existem bancos de dados que 
ofereçam uma lista de literatura em tradução. Infelizmente, não há trabalhos como esse que, através da cooperação entre dois grupos de pesquisa ligados às universidades de São Paulo e Santa Catarina, levaram ao mapeamento dos livros de literatura italiana traduzidos e impressos no Brasil, criando um catálogo eletrônico (Dicionário da Literatura Italiana Traduzida: www.dlit.ufsc.br; http://www.usp.br/ dlit). Na Itália, é possível fazer uma pesquisa bastante completa no catálogo do Opac (On-line Public Access Catalogue, https://opac.sbn. it), que, no entanto, fornece uma imagem não completa e não reflete, se não em parte, a real difusão e disponibilidade do título em questão.

Um fato positivo é que, nos últimos anos, o número de autores brasileiros traduzidos na Itália aumentou, dando espaço a vários autores contemporâneos que obtiveram algum sucesso. Se levássemos em consideração os contemporâneos 'clássicos' Paulo Coelho, Clarice Lispector e Jorge Amado ${ }^{27}$ ou os menos contemporâneos Machado de Assis e João Guimarães Rosa - apenas a título de exemplo estaríamos diante de uma situação bastante promissora que vê uma ampla disponibilidade de títulos em todo o território italiano. Mas, é importante lembrar que esses autores geralmente são publicados quase exclusivamente pelas grandes editoras e não refletem o estado geral de saúde da literatura brasileira na Itália, ou melhor, em italiano. Mesmo olhando para o controverso 'cânone', as edições italianas dos grandes clássicos brasileiros são bastante datadas e, consequentemente, as respectivas traduções resultam desatualizadas.

Sempre ligado ao clássico ou ao conhecido, o leitor italiano tem dificuldade para se aproximar das novidades e muitos mais dos autores brasileiros contemporâneos que são frequentemente publicados por pequenas editoras e isso, às vezes, afeta sua difusão real. Além disso, um fato fundamental a ser levado em consideração diz respeito à propensão do leitor italiano ao gênero romance, um leitor que não parece estar interessado em outros gêneros literários e que, portanto, dá pouco espaço para poesia, contos ou crônicas - gêneros muito prolífico na língua portuguesa -, nem para coleções antológicas que, quando existem, costumam ser edições para apreciadores e difíceis de divulgar, exceto em ambientes universitários, onde também é possível encontrar ensaios e obras filosóficas. Uma data importante, que impulsionou a tradução e recepção de produtos de língua portuguesa traduzidos para o italiano, foi o ano de 2006. A
27 Jorge Amado conta mais de trezentos produtos entre primeiras edições, retraduções ou reimpressões, superado apenas pelas mais de 400 edições italianas de Paulo Coelho - são na maioria grandes editoras que garantem uma certa correspondência entre o produto oferecido e o comprador. 
Feira Internacional do Livro de Turim homenageou Portugal e o Brasil também entrou entre os demais convidados especiais. $\mathrm{O}$ evento contou com a presença, entre outros, de Paulo Coelho, Bernardo de Carvalho, Moacyr Scliar e Milton Hatoum. Definitivamente, um eco importante que também atraiu a atenção de grandes editoras. Não devemos esquecer que existem pequenas editoras que têm, ou tiveram, o grande mérito de oferecer produtos de qualidade a preços adequados. Lembramos as duas editoras que mais traduziram autores brasileiros: Cavallo di Ferro e La Nuova Frontiera, além da editora Voland, que apresenta vários títulos (entre outros, Moacyr Scliar, Bernardo Carvalho e Rubem Fonseca).

Passando para uma breve revisão parcialmente ilustrativa e deliberadamente ignorando os autores considerados clássicos mencionados acima, é possível conciliar grandes nomes com uma difusão regular, como a de Rubem Fonseca - talvez um dos autores brasileiros mais famosos atualmente na Itália - com cerca de quinze títulos traduzidos. Mesmo Luiz Ruffato, com apenas quatro títulos em italiano, é bastante conhecido e apreciado, assim como Bernardo Carvalho. Traduções que certamente também derivam da conquista recente de importantes prêmios literários por esses autores.

A escrita feminina, muito florescente e interessante no Brasil de hoje, não se reflete particularmente na tradução italiana, com exceção para Adriana Lisboa (cinco títulos traduzidos) e Tatiana Salem Levy (dois romances traduzidos sempre pela editora Cavallo di Ferro Due fiumi, 2013 e La chiave di casa, 2011), ou Patrícia Melo (com quatro obras traduzidas). Também o autor de Porto Alegre, Daniel Galera, é bastante apreciado, assim como João Paulo Cuenca, embora, infelizmente, apenas dois títulos estejam disponíveis em italiano (Una giornata Mastroianni, Cavallo di ferro, 2008; Ho scoperto di essere morto, Miraggi, 2017) - obviamente também neste caso estamos lidando com dois romances, deixando de lado os inúmeros contos e crônicas produzidos pelos autores. Enquanto autores como Ferréz, Marcelino Freire, Altair Martins, Michel Laub permanecem praticamente ou completamente desconhecidos, assim como as vozes femininas de Andréa del Fuego, Ivana Arruda Leite, Letícia Wierzchowski Gomes, e muitas outras. Mesmo que o número de títulos traduzidos tenha aumentado e continua a aumentar nos últimos anos, é preciso verificar se isso corresponde a um aumento real na disseminação da literatura brasileira na Itália e, como primeira impressão, a resposta é negativa ou, 
de qualquer forma, não completamente positiva.

O contexto ideológico do sistema italiano deixa, como é óbvio, que certos autores brasileiros sejam aceitos e outros não. Talvez se possa argumentar que ainda existe uma busca pelo exotismo por parte do leitor italiano, ou uma atenção para a realidade violenta das favelas - uma produção ligada em particular ao final dos anos 1990 do século passado. Neste novo século, no entanto, os temas mudaram: por um lado, encontramos uma representação da violência que, no entanto, é frequentemente metropolitana e que lembra, ou melhor, se funde, com a violência de outras metrópoles mundiais; por outro, talvez tenhamos pela primeira vez de forma mais generalizada, uma representação das consequências da ditadura ${ }^{28}$. São, entre outros, dois temas muito importantes que talvez não atraiam ou não funcionem, para o leitor italiano. Poderíamos supor, mas é uma avaliação completamente subjetiva, que ainda existe uma visão estereotipada e simplificada do Brasil, que exige respostas simplistas e simplificadas que não ponham em causa o nosso ser 'europeus' e 'eurocêntricos'. Portanto, preferimos permanecer agarrados às nossas certezas e manter essa imagem totalmente tranquilizadora de um Brasil rural, exótico e carnavalesco.

\section{CONCLUSÕES}

Tentamos dar uma ideia da situação da leitura da literatura brasileira na Itália de hoje, a partir do ponto de vista sociológico, para tentar entender a recepção desta literatura pelos leitores italianos. Uma recepção bastante reduzida e sempre focada nos mesmos nomes e autores que resultam entre os mais vendidos em escala global. As escolhas editoriais e os sistemas de distribuição influenciam fortemente o consumo real, que por sua vez é condicionado pelo sucesso do autor (e muito pouco pela origem geográfica do mesmo ou pelo gênero literário em que uma obra se enquadra - mesmo que na Itália haja pouco espaço para poesia e, em geral, para gêneros narrativos que não sejam o romance). Existe uma espécie de curto-circuito entre produção, distribuição e consumo real, e isso certamente se deve ao fato dos leitores italianos serem poucos, rotineiros e pouco atentos às novidades. Autores brasileiros, especialmente contemporâneos, lutam para entrar no mercado editorial italiano. As grandes editoras tendem a publicar apenas best-sellers, enquanto editoras pequenas e
28 Lembramos apenas, a título de exemplo, que o escritor Bernardo Kucinski tem apenas um título traduzido para italiano: $K ., O$ La figlia desaparecida. Firenze: Giuntina, 2016. 
médias tentam propor novidades e se especializar em temas ou áreas geográficas, criando coleções de excelente qualidade, mas depois lutam para sobreviver aos custos sempre enormes. Uma situação que não é particularmente positiva, mas que esperamos possa melhorar nos próximos anos, convencidos de que uma educação à leitura - que inclua a abertura para 'outros' mundos como objetivo educacional-cultural -, é o caminho para uma mudança que leve ao surgimento de adultos e, portanto, cidadãos, mais conscientes.

\section{REFERÊNCIAS}

BARTHES, Roland. Il brusio della lingua. Torino: Einaudi, 1988.

BLOOM, Harold. O Cânone Ocidental. Rio de Janeiro: Objetiva, 1995.

CADIOLI, Antonio. La ricezione. Roma: Editori Laterza, 1998.

CASADEI, Alberto. La critica letteraria del Novecento. Bologna: Il Mulino, 2001.

CESERANI, Remo. Cannonate, Inchiesta-letteratura. Numero speciale I classici nella cultura e nell'editoria italiana contemporanea, ottobre-dicembre 1995, 67-74. Disponível em: http://www2.lingue.unibo.it/romanticismoold/membri/Ceserani/ Ceserani Remo.htm. Acesso em: Acesso em: 01 out. 2019.

ECO, Umberto. Lector in fabula. La cooperazione interpretativa nei testi narrativi. Milano: Bompiani, 2002.

FERRETTI, Gian Carlo. Storia dell'editoria letteraria in Italia. 1945-2003. Torino: Einaudi, 2004.

FRYE, Northrop. Anatomia della critica. Torino: Einaudi, 1969.

GARDINI, Nicola. Letteratura comparata. Milano: Mondadori Università, 2002.

ISER, Wolfgang. L'atto della lettura: una teoria della risposta estetica. Bologna: Il Mulino, 1989.

JAUSS, Hans Robert. Estetica della ricezione. Napoli: Guida, 1988.

LEFEVERE, André. Translation, History and Culture. A Sourcebook. London/New York: Routledge, 1992.

LÖWENTHAL, Leo. Letteratura, cultura popolare e società. Napoli: Liguori, 1977.

MOTTA, Federico. Editori e biblioteche nella filiera del libro: protagonisti e protagonismi. In: Bollettino AIB, 48(1), 2008, 63-66. Disponível em: https://bollettino. aib.it/issue/view/354/showToc. Acesso em: 01 out. 2019.

MOTTA, Uberto. Il canone letterario e il ruolo della scuola. In: Lineatempo - Rivista online di ricerca storica letteratura e arte, 10/2009, 1-6. Disponível em: http://www. diesse.org/cm-files/2009/05/31/3325.pdf. Acesso em: 01 out. 2019.

NERGAARD, Siri. Il canone e la traduzione. In: DE ZORDO, Ornella; FANTACCINI, Fiorenzo (Orgs.). Altri canoni/canoni altri, pluralismo e studi letterari. Firenze: Firenze University Press, 2011.

VOL. 16 | N.2 |DEZ. 2019 PARESCHI, Luca. La produzione editoriale in Italia: il processo di intermediazione 
nel Campo Letterario. Dottorato di ricerca in Direzione Aziendale, Ciclo XXII, Università di Bologna, 2011.

PISANTY, Valentina; PELLEREY, Roberto. Semiotica e interpretazione. Milano: Strumenti Bompiani, 2004.

REPORT ISTAT. Produzione e Lettura di Libri in Italia. [S.1.: s.n.], 2017. Disponível em: www.istat.it. Acesso em: 01 out. 2019.

SOLIMINE, Giovanni. Leggere dentro i dati sulla lettura in Italia. In: Bollettino AIB, 48(2/3), 2008, 233-248. Disponível em: https://bollettino.aib.it/issue/view/355/ showToc . Acesso em: 01 out. 2019,

VENUTI, Lawrence. La formazione delle identità culturali. In: BIANCHI, Cinzia; DEMARIA, Cristina; NERGAARD Siri (Orgs.). Spettri del potere. Ideologia, identità e traduzione negli studi culturali. Roma: Meltemi, 2002.

ZIMA, Pierre. Estetica della ricezione e sociologia della lettura. In: L'Immagine Riflessa, IX, 1986, 149-182.

ZINATO, Emanuele. Le idee e le forme: la critica letteraria in Italia dal 1900 ai nostri giorni. Roma: Carocci, 2010.

Doutora em Línguas, Literaturas e Culturas Estrangeiras (Língua e Literatura portuguesa), mestre em Línguas Estrangeiras Europeias e Euroamericanas, é atualmente investigadora de Língua portuguesa e brasileira na Universidade de Milão. Editou o estudo crítico La Ricezione Italiana di Fernando Pessoa tra mitizzazioni e appropriazioni (in)debite (2018), assim como artigos científicos sobre tradução literária, literatura portuguesa e cabo-verdiana contemporâneas. E-mail: elisa.alberani@unimi.it 